\title{
ASOCIACIÓN DEL LOCUS BOLA-DRB3.2 CON EL VIRUS DE LA LEUCOSIS BOVINA EN EL GANADO CRIOLLO COLOMBIANO
}

\section{ASSOCIATION BETWEEN THE LOCUS BOLA-DRB3.2 AND BOVINE LEUKEMIA VIRUS IN CREOLE COLOMBIAN BREEDS}

HERNÁNDEZ, H. DARWIN YOVANNY ${ }^{1}$ PhD*., MUÑOZ, F JAIME EDUARDO² PhD., ÁLVAREZ, F. LUZ ANGELA PhD.

${ }^{1}$ Grupo de Investigación en Reproducción y Mejoramiento Genético Animal, Facultad de Ciencias Agropecuarias, Universidad de Sucre, Sede Puerta Verde, Sucre, Colombia.

\section{Palavras Chave:}

Bovinos criollos, Complejo mayor de Histocompatibilidad,

Marcadores moleculares, Resistencia a enfermedades

\section{Resumo}

En 330 muestras de ADN de ocho razas bovinas criollas (Blanco Orejinegro, Caqueteño, Casanareño, Costeño con Cuernos, Chino Santandereano, Hartón del Valle, Romosinuano y Sanmartinero), dos razas sintéticas colombianas (Lucerna y Velásquez) y dos foráneas (Brahmán y Holstein) se evaluó la presencia del VLB (detección de provirus - PCR anidada), los polimorfismos del gen BoLA-DRB3.2* (PCR semianidada - RFLP) y la asociación entre ambos (OR). Se estimaron asociaciones entre la ausencia (resistentes) del VLB y los alelos *21, *24 y *37 y la presencia (susceptibles) del VLB y los alelos * 6 y ${ }^{*} 42$ en los ganados criollos. La frecuencia acumulada de los alelos resistentes fue de $23.7 \%$ contra $6 \%$ de los susceptibles. El 10\% de los individuos fue genotipificado como Resistente/ Resistente, el $2.5 \%$ como Susceptible/Susceptible y el $57 \%$ fue de genotipo homocigoto neutral $(N / N)$ en el ganado criollo colombiano. En los ganados controles el $16 \%$ fueron Resistente/Resistente y el $8.3 \%$ Susceptible/Susceptible. Los resultados indican que el ganado criollo colombiano posee genes de resistencia al VLB.

\section{Abstract}

The presence of the bovine leukemia virus (BLV) (pro-virus detection - Nested PCR), BoLA-DRB3.2* gen polymorphisms detection (Semi-nested PCR-RFLP) and the association between them (OR) were carried out in 330 DNA samples from eight creole breeds (Blanco Orejinegro, Caqueteño, Casanareño, Costeño con Cuernos, Chino Santandereano, Hartón del Valle, Romosinuano and Sanmartinero), two Colombian synthetic breeds (Lucerna y Velásquez) and two introduced ones (Brahmán y Holstein). A positive association was found between absence of BLV (resistant individuals) with alleles *21, ${ }^{*} 24$ and * 37 ; and the presence of BLV (susceptible individuals) with alleles ${ }^{*} 6$ and $* 42$. The cumulated allele frequency was $23.7 \%$ and $6 \%$ for the resistant and susceptible alleles respectively. For the Colombian creole cattle, $10 \%$ of genotyped individuals were classified as Resistant/ Resistant (RR), 2.5\% as Susceptible/Susceptible (SS) and $57 \%$ as neutral homozygous (N/N). For the introduced breeds, $16 \%$ were RR and $8.3 \%$ SS. The results indicate that the Colombian creole cattle has VLB resistance genes. 


\section{Introducción}

El Complejo Mayor de Histocompatibilidad de los bovinos es conocido como Antígenos de los Leucocitos Bovinos (BoLA) y se localiza en el cromosoma 23. El sistema BoLa es un conjuto de glicoproteínas que se ubican en la superficie celular y su función principal es la presentación de péptidos (TAKESHIMA y AIDA, 2006).

Existen tres clases de genes BoLA. Los BoLA clase I codifican proteínas implicadas en el reconocimiento de las células del hospedero que han sido infectadas y en la presentación de péptidos endógenos a las células citotóxicas T o T CD8+ (LEWIN, 2009; TAKESHIMA y AIDA, 2006).

Los genes BoLA clase Il están localizados en dos partes diferentes del cromosoma 23, posee dos regiones llamadas clase Ila y clase Ilb separadas por 15cM. La clase lla contiene los genes DR y $D Q$ y la clase Ilb los genes DYA, DYB, DMA, DMB, DOB, DOA, TAP1, TAP2, LAPM2 y LMP7. Estos genes producen glicoproteínas, implicadas en la comunicación entre las células $\mathrm{B}$ y $\mathrm{T}$, al igual, que procesos de presentación de antígenos extracelulares por las células presentadoras a las células T CD4 ${ }^{+}$y otras funciones inmunes (TAKESHIMA y AIDA, 2006).

Mientras que, los genes clase III codifican proteínas del sistema de complemento, moléculas relacionadas con la inflamación y proteínas de choque térmico (LEWIN, 2009).

Los genes y los productos de la región clase lla son los más estudiados porque presentan altos niveles de polimorfismo. Se han identificados 14 genes en esta región: DRA, DRB (DRB1, DRB2, DRB3), DQA (DQA1, DQA2, DQA3, DQA4, DQA5) y DQB (DQB1, DQB2, DQB3, DQB4, DQB5) (TAKESHIMA y AIDA, 2006), donde el gen DRB3 es el más estudiado, este tiene una longitud de 11,4 Kbp con cinco intrones y seis exones, de los cuales el más polimórfico es el exón dos (BoLA-DRB3.2) de un tamaño aproximado de 270 bp (RUSSELL et al., 2004).

El gen DRB3.2 ha sido asociado con caracteres productivos (NASCIMENTO et al., 2006; ZAMBRANO et al., 2009a) y con enfermedades (GÓMEZ et al., 2006; JULIARENA et al., 2008; PANEI et al., 2009).

La leucosis bovina enzoótica (LBE), es una enfermedad infecciosa producida por un retrovirus, el virus de la leucosis bovina (VLB), que afecta las células de la línea linfoide, esta se caracteriza por el aumento bilateral más o menos simétrico de los ganglios linfáticos explorables (linfosarcoma, LS; linfoma maligno, LM) (SCHELL et al., 2004), masas tumorales subcutáneas en diferentes localizaciones (linfoadenopatías), la exoftalmia puede considerarse como una manifestación específica de la enfermedad (CHAMIZO, 2005) al igual que, un incremento sostenido del número absoluto de linfocitos en la corriente sanguínea (linfocitosis persistente, LP) (MALATESTINIC, 2003).

EI VLB pertenece al grupo de los Retroviridae, posee una transcriptasa-reversa responsable de la síntesis de una copia de ADN a partir de ARN viral. EI ADN formado llamado provirus, puede conservarse en el núcleo de las células infectadas del hospedero. El virus se transmite de forma horizontal o por vía iatrogénica. La manifestación clínica de LBE comienza generalmente dos años después de la infección, con sintomas como: anemia, emaciación e infertilidad (BEYER et al., 2002).

El diagnóstico se realiza comúnmente por radioinmunoensayo (RIA), inmunodifusión en gel de agar (IGDA) y ensayo de inmunoabsorción ligado a enzimas (ELISA). Estas técnicas presentan la desventaja de no poder detectar la infección en animales jóvenes o en estadíos tempranos de infección. La PCR ha sido utilizada para la detección temprana del VLB en animales menores de seis meses evitando así reacciones falso positivas, otra ventaja radica en la capacidad para detectar el virus en animales inmunotolerantes (CHAMIZO, 2005).

Los estudios sobre la presencia de la LBE en Colombia son variables, dependiendo de la región de muestreo de los animales y de la técnica serológica utilizada. En el Nororiente del país el porcentaje de presencia varía entre el 3.9 y el $14.64 \%$ utilizando la técnica de inmunodifusión en gel de agar (IGDA) (RUIZ, 1995). También se reportan una presencia de $37.5 \%$ en novillas y un $71.9 \%$ en vacas en el departamento de Antioquia (RAMÍREZ et al., 2002). En el departamento de Córdoba se encontró un $21.5 \%$ de positivos utilizando la técnica de ELISA (BETANCUR y RODAS, 2008), mientras que en la Sabana de Bogotá se reportó un $45.28 \%$ presencia (ALFONSO et al., 1998). Se encontraron prevalencias en ganado de leche de $24.9 \%$ para la región Andina, $14.4 \%$ para la región Caribe y $15.3 \%$ para el piedemonte Llanero (GRIFFITHS et al., 1995). Utilizando métodos moleculares (PCR-anidado) se reportan $25 \%$ de presencia del virus en ganados del Valle del Cauca (MUÑOZ et al., 2008).

El objetivo del presente trabajo fue asociar los alelos del gen BoLA-DRB3.2 con la infección por el Virus de la Leucosis Bovina en las razas criollas y colombianas.

\section{Materiales y métodos}

Del banco de ADN del Laboratorio de Genética Animal de la Universidad Nacional de Colombia sede Palmira, se tomaron 30 muestras de ADN de cada una de las 
razas utilizadas, así: criollo ((Blanco orejinegro (BON), Casanareño (CAS), Costeño con cuernos (CCC), Chino Santandereano (ChS), Caqueteño (CQT), Sanmartinero (SM), Romosinuano (RS) y Hartón del Valle (HV)), de cada raza sintética colombiana (RSC) (Velásquez (VEL) y Lucerna (LUC)) y de las razas foráneas Holstein $(\mathrm{H})$ y Brahmán (B), teniendo en cuenta que no fueran animales emparentados, para un total de 360 muestras.

La detección de los animales infectados con el virus de la leucosis bovina se realizó mediante la detección del provirus, amplificando una región altamente conservada del gen env viral utilizando la técnica PCR-anidada, descrita en artículo previo (HERNÁNDEZ et al., 2011). En resumen: la primera reacción de PCR se realizó a un volumen final de $30 \mu \mathrm{l}$ conteniendo $100 \mathrm{ng}$ de ADN $1,25 \mathrm{mM}$ de cada oligonucleótido (5'-TCTGTGCCAAGTCTCCCAGATA-3' y 5'-AACAACAACCTCTGGGGAGGGT-3'), 0,2mM de cada dNTP, 1 X de tampón PCR, 2,5mM MgCl y $1 \mathrm{U}$ de Taq DNA Polimerasa (Fermentas $®)$. En la segunda reacción se utilizó como ADN molde $3 \mu$ l del producto de PCR de la primera amplificación con las mismas concentraciones de los otros reactivos y los oligonucleótidos 5' - C C CACAAGGGCGGCGCCGGTTT-3' y 5'-GCGAGGCCGGGTCCAGAGCTGG-3'. Los perfiles térmicos incluyeron una etapa de desnaturalización inicial a $94^{\circ} \mathrm{C}$ por 5 minutos, seguido por 40 ciclos de $94^{\circ} \mathrm{C}$ por 30 segundos, $57^{\circ} \mathrm{C}$ por 30 segundos y $72^{\circ} \mathrm{C}$ por 1 minuto, para terminar con una extensión final a $72^{\circ} \mathrm{C}$ por 5 minutos. En la segunda reacción las condiciones fueron las mismas, excepto que la temperatura de hibridación se aumentó a $68^{\circ} \mathrm{C}$. Todas las amplificaciones se llevaron a cabo en un termociclador PTC-100® Teltier Thermal Cycler, BIO-RAD. Para la visualización de los productos amplificados se realizaron geles de agarosa al 1.2\% teñido con bromuro de etidio en una cámara SUBCELL $\circledast$ GT, BIO-RAD. La presencia de una banda de 444bp indicó que el animal estaba infectado con el VLB.

Los alelos del gen BoLA-DRB3.2 se determinaron utilizando la metodología PCR-RFLP descrita en detalle por HERNÁNDEZetal. (2013). Rápidamente: se amplificó el segundo exón del gen BoLA-DRB.3, por un protocolo de PCR de dos pasos (semi-anidado); con los cebadores: HL030 (5'-ATCCTC TCTCTGCAGCACATTTCC-3'), HL031 (5'-TTTAAATTCGCGCTCACCTCGCCGCT-3'), HL032 (5'-TCGC CGCTCAGTGAAACTCTC-3'); en la primer reacción de amplificación se utilizaron los oligonucleótidos HL030 y HL031 (1.25mM), en $25 \mu \mathrm{l}$ de mezcla total, con $20 \mathrm{ng}$ de ADN, $0.2 \mathrm{mM}$ de cada dNTP, 1 X de tampón PCR, $2.5 \mathrm{mM} \mathrm{MgCl}_{2}$ y $1 \mathrm{U}$ de Taq DNA Polimerasa (Fermentas $\AA$ ). El programa de amplificación constó de una desnaturalización inicial de 4 minutos a $94^{\circ} \mathrm{C}, 10$ ciclos de 1 minuto a $94^{\circ} \mathrm{C}, 2$ minutos a $60^{\circ} \mathrm{C}$ y 1 minuto a $72^{\circ} \mathrm{C}$, con una extensión final de 5 minutos a $72^{\circ} \mathrm{C}$. Para la segunda reacción se tomaron $4 \mu \mathrm{l}$ de la primera reacción de PCR como molde y los oligonucleótidos HL030 y HL032 en un volumen total de $50 \mu \mathrm{l}$, con las mismas concentraciones de los otros reactivos. El programa de amplificación constó de una desnaturalización inicial de 4 minutos a $94^{\circ} \mathrm{C}$ y 25 ciclos de 1 minuto a $94^{\circ} \mathrm{C}, 30$ segundos $65^{\circ} \mathrm{C}$ y 1 minuto a $72^{\circ} \mathrm{C}$, con una extensión final de 5 minutos a $72^{\circ} \mathrm{C}(7)$. Todas las amplificaciones se realizaron en un termociclador marca PTC-100 ${ }^{\circledR}$ (Peltier Thermal Cycler BIO-RAD). El producto de ambas reacciones fue una banda de 282 pares de bases. 10 $\mu$ l del producto de PCR de la segunda reacción se utilizaron como sustrato para la digestión con $5 \mathrm{U}$ de las enzimas Rsal, Bstyl y HaellI (Fermentas ${ }^{\circ}$ ) a $37^{\circ} \mathrm{C}$ durante 4 horas. La electroforesis se realizó en geles de agarosa SFR ${ }^{\mathrm{TM}}$ (Super Fine Resolution, AMRESCO $®$ ) al $3 \%$ y teñidos con bromuro de etidio en una cámara SUB-CELL® GT (BIO-RAD). La lectura de los alelos se basó en la nomenclatura del 5th BoLA workshop (ISAG, 2010).

Para el análisis estadístico se formaron los siguientes grupos: criollos (BON, CAS, CCC, ChS, CQT, HV, RS y SM. $n=240$ ), sintéticas (LUC y VEL. $n=60$ ) y foráneas (B y H. $n=60$ ). El ganado criollo colombiano (GCC) está formado por las razas criollos y las razas sintéticas $(n=300)$. Se determinó el porcentaje de presencia del VLB, el número de alelos y sus frecuencias para cada raza usando el programa ALERQUIN versión 3.5 (EXCOFFIER y LISCHER, 2010). Se realizó una prueba de chi-cuadrado $\left(X^{2}\right)$ para determinar la dependencia entre la presencia del VLB y los alelos DRB3.2*, la asociación entre la presencia del virus y los alelos del gen DRB3.2* se determinó con el estadístico Odds Ratio (OR) (JULIARENA et al., 2008) seguido de un test exacto de Fischer para determinar la significancia estadística del valor de OR utilizando el software SAS versión 9.1. Los alelos se categorizaron según el grado asociación en: positiva $(O R>1, p<0.05)$ y se consideraron como resistentes $(R)$ a la presencia del VLB, negativa $(O R<1, p<0.05)$ y se consideraron susceptibles (S) a la presencia del VLB y los demás alelos como neutrales $(\mathrm{N})(\mathrm{OR} \sim 1, \mathrm{p}>0.05)$. Los individuos fueron clasificados según la categoría de sus alelos, resultando las categorías: neutral/neutral (NN), neutral/resistente (NR), neutral/susceptible (NS), resistente/resistente (RR), resistente/susceptible (RS) y susceptible/susceptible (SS).

\section{Resultados}

El porcentaje de presencia del VLB fue mayor en las razas $\mathrm{HV}$ y $\mathrm{ChS}(83.3 \%$ y $60 \%$ respectivamente); las razas VEL y LUC tuvieron el mismo porcentaje de presencia $(50 \%)$; en las razas CAS, CCC y CQT la presencia del virus fue de $26,7 \%, 23.3 \%$ y $16.7 \%$ respectivamente; no se encontró presencia del virus en 
las razas BON, SM y RS. El las razas foráneas el VLB se encontró en $83.3 \%$ en $\mathrm{H}$ y $6.7 \%$ en $\mathrm{B}$. El promedio de presencia del VLB en el GCC (31\%) fue menor que el promedio en las razas foráneas (45\%). Resultados en detalle se muestran en HERNÁNDEZ et al. (2011).

Se encontraron 41 alelos BoLA-DRB3.2* , de los cuales 20 también estuvieron presentes en las razas foráneas. El numero promedio de alelos para el GCC 14.6 \pm 3.8 y para las foráneas de $15 \pm 1.41$. El CQT presentó el mayor número de alelos ( 25 alelos) y el $\mathrm{ChS}$ el menor (10 alelos), mientras que en las razas sintéticas el mayor número de alelos lo presento LUC (13 alelos) y en las razas foráneas B (16 alelos). El $58 \%$ de los alelos encontrados en el ganado GCC y el $36 \%$ en las foráneas tuvieron frecuencias menores a $5 \%$. Los alelos con frecuencias superiores a $5 \%$ en el GCC fueron: DRB3.2 *28 (0.150 \pm 0.014$),{ }^{*} 37(0.128 \pm 0.013),{ }^{*} 24$ $(0.089 \pm 0.011),{ }^{*} 23(0.093 \pm 0.012) \mathrm{y} * 20(0.078 \pm 0.011)$. En las razas foráneas los alelos con frecuencia mayor al $5 \%$ fueron los BoLA-DRB3.2 * $13(0.167 \pm 0.035),{ }^{*} 37$ $(0.150 \pm 0.033),{ }^{*} 36(0.090 \pm 0.026),{ }^{*} 23(0.079 \pm 0.025)$, *28 (0.061 \pm 0.022$)$ y el *25 $(0.052 \pm 0.021)$. Los resultados en detalle se muestran en HERNÁNDEZ et al. (2013).

La prueba de independencia de chi-cuadrado $\left(\mathrm{X}^{2}\right)$ entre la presencia del virus y los alelos DRB3.2* mostró dependencia altamente significativa entre ambos $\left(X^{2} c=345.99, p<0.01\right)$.

En el GCC, el OR determinó asociaciones positivas entre los alelos DRB3.2 *21, *24 y *37 con ausencia del virus y asociaciones negativas entre los alelos * 6 y *42 con la presencia del virus $(p<0.05)$, el resto de los alelos se consideraron neutrales a la infección. En las razas foráneas el alelo *13 tuvo asociación positiva y los alelos *23 $\mathrm{y}$ *28 asociación negativa $(p<0.05)$. El GCC y los ganados foráneos no compartieron alelos con la misma clasificación (Tablas 1 y 2).

Tabla 1. Valores de OR, intervalo de confianza (95\%), significancia y categoría de los alelos asociados con la presencia del VLB.

\begin{tabular}{|c|c|c|c|c|c|c|c|}
\hline \multirow[b]{2}{*}{ Alelo } & \multicolumn{6}{|c|}{ GCC } & \multirow[b]{2}{*}{ Categoría } \\
\hline & $\begin{array}{l}\text { Presencia } \\
\text { del VLB }\end{array}$ & $\begin{array}{c}\text { Ausencia } \\
\text { del VLB }\end{array}$ & OR & \multicolumn{2}{|c|}{$\begin{array}{c}\text { Intervalo de } \\
\text { confianza (95\%) }\end{array}$} & $\begin{array}{l}\text { Test de } \\
\text { Fischer }\end{array}$ & \\
\hline${ }^{*} 6$ & 6 & 2 & 0,4 & 0,018 & 0,905 & 0,02 & $S^{1}$ \\
\hline *21 & 1 & 15 & 4,13 & 1.273 & 15,23 & 0,03 & $R^{2}$ \\
\hline *24 & 13 & 37 & 7,19 & 1.377 & 11,560 & 0,035 & $R$ \\
\hline *37 & 16 & 60 & 7,51 & 1.678 & 10,870 & 0,02 & $R$ \\
\hline *42 & 7 & 4 & 0,36 & 0,011 & 0,095 & 0,04 & $S$ \\
\hline \multicolumn{8}{|c|}{ Foráneas } \\
\hline *13 & 2 & 17 & 8,78 & 1.019 & 16,74 & 0,001 & $R$ \\
\hline *23 & 7 & 2 & 0,11 & 0,025 & 0,527 & 0,035 & $S$ \\
\hline${ }^{\star} 28$ & 6 & 1 & 0,12 & 0,026 & 0,542 & 0,041 & $S$ \\
\hline
\end{tabular}

Tabla 2. Frecuencia de los alelos DRB $3.2^{*}$ asociados con la presencia del virus, número de alelos (NA) y presencia del VLB en el GCC.

\begin{tabular}{|c|c|c|c|c|c|c|c|c|}
\hline \multirow{2}{*}{ Grupo } & \multirow{2}{*}{ Raza } & \multicolumn{5}{|c|}{ Alelos/Categoría } & \multirow{2}{*}{ NA $^{3}$} & \multirow{2}{*}{$\begin{array}{c}\text { Presencia } \\
\text { del } \\
\text { VLB (\%) }\end{array}$} \\
\hline & & ${ }^{\star} 21 / R^{1}$ & ${ }^{*} 24 / R$ & *37/R & ${ }^{*} 6 / S^{2}$ & *42/S & & \\
\hline \multirow{8}{*}{ Criollos } & BON & $\begin{array}{l}0.071 \\
\pm 0.03\end{array}$ & $\begin{array}{l}0.053 \\
\pm 0.03\end{array}$ & $\begin{array}{l}0.250 \\
\pm 0.06\end{array}$ & & & 15 & 0 \\
\hline & CAS & & $\begin{array}{l}0.070 \\
\pm 0.03\end{array}$ & $\begin{array}{l}0.103 \\
\pm 0.04\end{array}$ & $\begin{array}{l}0.034 \\
\pm 0.02\end{array}$ & & 17 & 26,7 \\
\hline & $\mathrm{CcC}$ & & $\begin{array}{l}0.153 \\
\pm 0.05\end{array}$ & $\begin{array}{l}0.020 \\
\pm 0.01\end{array}$ & & & 12 & 23,3 \\
\hline & ChS & & $\begin{array}{l}0.071 \\
\pm 0.03\end{array}$ & $\begin{array}{l}0.160 \\
\pm 0.05\end{array}$ & & & 10 & 60 \\
\hline & CQT & & & $\begin{array}{l}0.103 \\
\pm 0.04\end{array}$ & & $\begin{array}{l}0.034 \\
\pm 0.02\end{array}$ & 25 & 16,7 \\
\hline & HV & $\begin{array}{l}0.020 \\
\pm 0.01\end{array}$ & $\begin{array}{l}0.050 \\
\pm 0.03\end{array}$ & $\begin{array}{l}0.067 \\
\pm 0.03\end{array}$ & $\begin{array}{l}0.083 \\
\pm 0.04\end{array}$ & $\begin{array}{l}0.100 \\
\pm 0.04\end{array}$ & 14 & 83,3 \\
\hline & RS & $\begin{array}{l}0.100 \\
\pm 0.04\end{array}$ & & $\begin{array}{l}0.050 \\
\pm 0.03\end{array}$ & & $\begin{array}{l}0.020 \\
\pm 0.01\end{array}$ & 16 & 0 \\
\hline & SM & & $\begin{array}{l}0.350 \\
\pm 0.06\end{array}$ & $\begin{array}{l}0.067 \\
\pm 0.03\end{array}$ & & & 12 & 0 \\
\hline \multirow{2}{*}{ Sintéticos } & LUC & & $\begin{array}{l}0.051 \\
\pm 0.03\end{array}$ & $\begin{array}{c}0.33 \\
\pm 0.06\end{array}$ & $\begin{array}{l}0.020 \\
\pm 0.01\end{array}$ & $\begin{array}{l}0.034 \\
\pm 0.02\end{array}$ & 13 & 50 \\
\hline & VEL & & & $\begin{array}{l}0.133 \\
\pm 0.04\end{array}$ & & & 12 & 50 \\
\hline \multicolumn{2}{|c|}{$\begin{array}{c}\text { Frecuencia/ } \\
\text { Promedio }\end{array}$} & $\begin{array}{c}0.020 \\
\pm 0.005\end{array}$ & $\begin{array}{c}0.089 \\
\pm 0.011\end{array}$ & $\begin{array}{c}0.128 \\
\pm 0.013\end{array}$ & $\begin{array}{c}0.013 \\
\pm 0.004\end{array}$ & $\begin{array}{c}0.020 \\
\pm 0.005\end{array}$ & $\begin{array}{l}14.6 \\
\pm 3.8\end{array}$ & 31 \\
\hline
\end{tabular}

${ }^{1} \mathrm{R}=$ Resistentes, ${ }^{2} \mathrm{~S}=$ Susceptibles, ${ }^{3} \mathrm{NA}=$ Número de alelos

Los alelos *21, *24 y *37 considerados como $R$ presentaron una frecuencia acumulada de $23.7 \%$, mientras que, los alelos S ( ${ }^{*} 6$ y $\left.{ }^{*} 42\right)$ su frecuencia acumulada fue de $6 \%$, y la frecuencia acumulada de los alelos N (36 alelos) fue del $70.3 \%$.

El alelo *21 solo se encontró en las razas BON, HV y RS. El alelo *24 no se encontró en las razas CQT, RS y VEL. El alelo *37 se encontró en todas las razas. En contraste, los alelos con asociación negativa, el *6 solo estuvo presente en tres razas (CAS, HV y LUC) y el *42 se encontró en CQT, HV, RS y LUC. Todas las razas que conforman el GCC presentaron al menos un alelo de $\mathrm{R}$ con frecuencia mayor al $5 \%$ (Tabla 1 ).

En los ganados foráneos solo el alelo *13 presentó asociación positiva, este solo se encontró la raza $\mathrm{B}$ con alta frecuencia $(0.327 \pm 0.06)$. De otro lado, los alelos con asociación negativa fueron el *23 y el *28. El alelo *28 solo se encontró en el $\mathrm{H}(0.125 \pm 0.04)$ y el ${ }^{*} 23$ en las dos razas foráneas $(0.012 \pm 0.04$ en $\mathrm{H}$ y $0.034 \pm 0.02$ en $\mathrm{B})$.

Los animales fueron clasificados según la categoría dada a cada uno de los alelos ( $N, R$ o S), así: neutral/ neutral (NN), neutral/resistente (NR), neutral/susceptible (NS), resistente/resistente (RR), resistente/susceptible (RS) y susceptible/susceptible (SS).

En el GCC el $10.2 \%$ de los animales fue RR y solo el $2.5 \%$ SS (Tabla 3 ). Las categorías con mayor porcentaje de individuos fueron NN y NR con $57.9 \%$ y 
$27.6 \%$ respectivamente. Los porcentajes más bajos se presentaron en las categorias NS (1.2\%) y RS (0.7\%). En los ganados foráneos el mayor porcentaje de individuos estuvo en la categoría NN (63.3\%), seguido por los RR $(16.6 \%)$, en NS y SS $(8.3 \%)$, en NR $(3.3 \%)$ y $0 \%$ en RS (Tabla 3 ).

Tabla 3. Porcentaje de animales en cada categoría según la resistencia y susceptibilidad al VLB en el GCC y las razas foráneas.

\begin{tabular}{|c|c|c|c|c|c|c|c|}
\hline \multirow{2}{*}{ Grupo } & \multirow{2}{*}{ Raza } & \multicolumn{6}{|c|}{ Genotipos (\%) ${ }^{*}$} \\
\hline & & NN & NR & NS & RR & RS & ss \\
\hline \multirow{9}{*}{ Criollos } & BON & 39,4 & 46,4 & 0 & 14,2 & 0 & 0 \\
\hline & CAS & 72 & 8 & 4 & 16 & 0 & 0 \\
\hline & CcC & 69,1 & 27 & 0 & 3,9 & 0 & 0 \\
\hline & Chs & 53,5 & 42,8 & 0 & 3,7 & 0 & 0 \\
\hline & & & & & & & \\
\hline & CQT & 75,8 & 20,7 & 0 & 0 & 0 & 3,5 \\
\hline & HV & 55,3 & 20,2 & 0 & 0 & 7 & 17,5 \\
\hline & RS & 72 & 16 & 4 & 8 & 0 & 0 \\
\hline & SM & 39,3 & 35,7 & 0 & 25 & 0 & 0 \\
\hline \multirow{2}{*}{ Sintéticas } & LUC & 35,7 & 35,7 & 3,6 & 21,4 & 0 & 3,6 \\
\hline & VEL & 66,7 & 23,3 & 0 & 10 & 0 & 0 \\
\hline \multicolumn{2}{|c|}{ Promedio } & 57,9 & 27,6 & 1,2 & 10,2 & 0,7 & 2,5 \\
\hline \multirow{3}{*}{ Foráneas } & B & 63,3 & 3,4 & 0 & 33,3 & 0 & 0 \\
\hline & & & & & & & \\
\hline & H & 63,3 & 3,3 & 16,7 & 0 & 0 & 16,7 \\
\hline \multicolumn{2}{|c|}{ Promedio } & 63,3 & 3,4 & 8,4 & 16,7 & 0 & 8,4 \\
\hline
\end{tabular}

En todas las razas del presente estudio la mayoría de los individuos se clasificó como NN. Individuos RR no se encontraron en CQT y HV, igualmente solo individuos SS se encontraron en estas razas además de en el LUC y en el $\mathrm{H}$, mientras que, el RS solo se encontró en HV. De 148 animales que tuvieron categoría NN el $27.7 \%$ estuvieron infectados por el VLB y el $72.3 \%$ no tuvieron infección. En contraste, los animales RS que presentaron el VLB fueron el $71.4 \%$ y los que no el $28.6 \%$.

La combinación de dos alelos $R(R / R)$ y la combinación de un alelo $\mathrm{R}$ con otro de alelo de cualquier categoría (R/Otro), hizo que los genotipos se comportaran como resistentes $(p<0.01)$, con un valor de OR más alto para el genotipo R/Otro. El genotipo Otro/Otro se comportó de manera neutral a la infección al VLB (Tabla 4).

En la categoría de susceptibles, el genotipo S/Otro presentó un valor de OR de $1.05(p<0.01)$ lo que hace que el genotipo tienda a ser neutral a la infección, el $\mathrm{S} / \mathrm{S}$ fue muy susceptible a la infección $(\mathrm{OR}=0.13$, $p<0.01)$ y el genotipo Otro/Otro presento un valor de OR alto. (Tabla 4).

Tabla 4. Valores de OR, intervalo de confianza (95\%) y significancia de los genotipos formados de acuerdo a la categoría asignada a los alelos.

\begin{tabular}{|c|c|c|c|c|c|c|c|}
\hline \multirow{2}{*}{$\begin{array}{l}\text { Categoría } \\
\text { Resistentes }\end{array}$} & \multirow{2}{*}{$\begin{array}{c}\text { Genotipo } \\
\text { R/R }\end{array}$} & \multirow{2}{*}{$\begin{array}{c}\begin{array}{c}\text { Ausencia, } \\
\%\end{array} \\
78,5\end{array}$} & \multirow{2}{*}{$\begin{array}{c}\begin{array}{c}\text { Presencia, } \\
\%\end{array} \\
21,5\end{array}$} & \multirow{2}{*}{$\begin{array}{c}\text { OR } \\
2,77\end{array}$} & \multicolumn{2}{|c|}{$\begin{array}{l}\text { Intervalo de } \\
\text { confianza } \\
(95 \%)\end{array}$} & \multirow{2}{*}{$\begin{array}{c}\text { Test de } \\
\text { Fischer }\end{array}$} \\
\hline & & & & & 1,86 & 4,97 & \\
\hline & R/otro & 74 & 26 & 6,55 & 5,47 & 9,53 & 0,005 \\
\hline & Otro/Otro & 66,7 & 33,3 & 1,22 & 1,01 & 2,54 & 0,125 \\
\hline \multirow[t]{3}{*}{ Susceptibles } & $S / S$ & 20 & 80 & 0,13 & 0,09 & 0,25 & 0,006 \\
\hline & S/otro & 37,5 & 62,5 & 1,05 & 1,01 & 1,99 & 0,001 \\
\hline & Otro/Otro & 72,5 & 27,5 & 4,38 & 3,98 & 6,25 & 0,001 \\
\hline
\end{tabular}

\section{Discusión}

En el presente trabajo se determinó la asociación entre la infección con el VLB y los polimorfismos del gen BoLA-DRB3.2*. Los porcentajes de presencia del VLB son mayores a los porcentajes de presencia del LBE (ALFONSO et al., 1998, BETANCUR y RODAS, 2008, GRIFFITHS et al., 1995, RAMÍREZ et al., 2002, RUIZ, 1995)., lo que está directamente relacionado con el método de diagnóstico utilizado (PCR-anidado), pues los métodos diagnósticos basados en serología requieren además de la infección un tiempo de incubación en el animal desarrolle anticuerpos contra el virus (HERNÁNDEZ et al., 2011).

El número de alelos y sus frecuencias son similares a los reportados en otros ganados criollos (FERNÁNDEZ et al., 2008; GIOVAMBATTISTA et al., 1996; KELLY et al., 2003; RIPOLI et al., 2004) y en razas foráneas presentes en América (JULIARENA et al., 2008; MARTÍNEZ et al., 2005; NASCIMENTO et al., 2006; PANEl et al., 2009; ZAMBRANO et al., 2009b). Otros estadísticos relacionados con la diversidad genética del locus BoLA-DRB3.2* en estas mismas muestras se presentan en artículo previo (HERNÁNDEZ et al., 2013).

Algunos polimorfismos en el gen BoLA-DRB3 se han relacionado con el desarrollo de resistencia o susceptibilidad a la Leucosis Bovina producida por VLB. Los primeros estudios revelaron que la presencia de los aminoácidos Glu-Arg (motivo ER) en la posición 70-71 de la cadena BoLA-DR $\beta$ estaba asociado con resistencia a la linfocitosis persistente (LP) producida por la infección con VLB, los alelos que codifican el motivo ER son *11, *23 y *28 (XU et al., 1993). Estudios posteriores confirmaron la asociación de los alelos *11, *23 y *28 con resistencia a LP y de los alelos *8, *16, *22 y *24 con susceptibilidad a la LP (PANEl et al., 2009; 
SULIMOVA et al., 1995; ZANOTTI et al., 1996). De los alelos de resistencia a la LP, solo el *11 se encontró en el CQT, mientras que, los alelos *23 y *28 están en todas las razas criollas (HERNÁNDEZ et al., 2013).

Los alelos de resistencia a la infección del VLB que aquí mostramos y los de resistencia al desarrollo de LP (PANEl et al., 2009; SULIMOVA et al., 1995; ZANOTTI et al., 1996) fueron diferentes, sin embargo, el alelo *24 relacionado como susceptible al desarrollo de LP, aquí fue relacionado con resistencia a la infección por VLB, lo anterior puede indicar que animales con este alelo una vez infectados desarrollan rápidamente LP, esto sugiere que el control del desarrollo y/o progresión de la LBE está influenciada por otros alelos de este gen.

El motivo ERV en las posiciones 74, 77 y 78 (Glu-ArgVal) de la cadena DR $\beta$ ha sido asociado con resistencia al desarrollo de tumores (GILLET et al., 2003). Algunos alelos que tienen este motivo son el *11 y el *23, en el presente estudio estos alelos presentaron una asociación neutral, es importante destacar que el alelo *23 se encontró en todas las razas del GCC y el *11 solo en la raza $\mathrm{QCT}$.

Por otro lado se ha relacionado positivamente los alelos *11 y *12 con baja carga proviral y el alelo *16 con alta carga (JULIARENA et al., 2008). Estos alelos resistentes solo se encontraron en las razas CQT y CAS, mientras que, el *16 presentó alta frecuencia en el RS $(0.133 \pm 0.04)$. Los alelos de resistencia/susceptibilidad a la carga proviral mostrados por JULIARENA et al. (2008) son diferentes a los presentados en este trabajo, como resisntes a la infección por VLB determinada molecularmente, esto apunta a que la infección con el VLB y la subsecuente multiplicación viral está controlada por diferentes alelos del gen DRB3.

Todas las razas de GCC presentaron alto porcentaje de individuos con genotipo NN y NR y no se encontraron individuos $\mathrm{RR}$ en el HV lo que se reflejó en los porcentajes de presencia del VLB.
La asociación entre el desarrollo de la leucosis bovina y el genotipo DRB3, mostró un fuerte efecto protector en los animales heterocigotos (R/Otro y S/Otro). Estos resultados sugieren una ventaja del heterocigoto. Se ha propuesto que los individuos heterocigotos para el $\mathrm{CMH}$ son capaces de reconocer un amplio espectro de antígenos, aumentando así la eficiencia de estos individuos en comparación con individuos homocigotos (HEDRICK et al., 1991; HUGHES y NEI, 1989). Varios estudios han demostrado que la heterocigocidad confiere ventajas selectivas contra enfermedades infecciosas, por ejemplo, humanos heterocigotos en locus HLA clase II mostraron tener resistencia contra el virus de la hepatitis $B$ y el virus de la inmunodeficiencia humana (VIH) (CARRINGTON et al., 1999; HRABER et al., 2007). En bovinos Holstein con mastitis causada por Escherichia o Streptococcus se encontró que en los animales heterocigotos en el locus clase II DQA1, la progresión de la enfermedad era más lenta (BAXTER et al., 2008; TAKESHIMA et al., 2008). Un resultado similar de ventaja del heterocigoto sobre el control de la carga proviral del VLB también es demostrado y propuesto por MIYASAKA et al. (2013).

Estos resultados sugieren que el desarrollo de leucosis bovina es una característica cuantitativa, con dominancia de los alelos de resistencia, igualmente, la alta frecuencia acumulada de los genes de resistencia a la infección en el GCC pueden ser utilizados en programas de mejoramiento genético con el fin de aumentar la resistencia genética al virus.

Finalmente, los datos indican que posiblemente el proceso de infección con VLB y el desarrollo de síntomas propios de la LBE tales como la LP, aumento/disminución carga proviral y el desarrollo de tumores están bajo el control de diferentes alelos del complejo BoLA-DRB3.2*, es necesario evaluar esta hipótesis, más aun, en las razas criollas Colombianas donde varios señalan que estas son resistentes a diferentes enfermedades.

Agradecimientos: Ala Dirección Nacional de Investigación de la Universidad Nacional de Colombia por la financiación del proyecto.

\section{Referencias}

ALFONSO, R.; ALMANSA, J.; DEL C BARRERA, J. 1998. Prevalencia serológica y evaluación de los factores de riesgo de la leucosis bovina enzoótica en la Sabana de Bogotá y los Valles de Ubaté y de Chiquinquirá, Colombia. Revue scientifique et technique - Office international des épizooties 17:723-732.

BAXTER, R.; HASTINGS, N.; LAW, A.; GLASS, E. A. 2008. A rapid and robust sequence-based genotyping method for BoLA-DRB3 alleles in large numbers of heterozygous cattle. Anim Genet. 39:561-563.

BETANCUR, C.; RODAS, J. 2008. Seroprevalencia de la leucosis viral bovina en animales con trastornos reproductivos de Montería. Revista MVZ Córdoba 13:1197-1204. 
BEYER, J.; KÖLLNER, B.; TEIFKE, J.; STARICK, E.; BEIER, D.; REIMANN, I. 2002. Cattle Infected with Bovine Leukaemia Virus may not only Develop Persistent B-cell Lymphocytosis but also Persistent B-cell Lymphopenia. Journal of Veterinary Medicine Series B 49:270-277.

CARRINGTON, M.; NELSON, G.; MARTIN, M.; KISSNER, T.; VLAHOV, D.; GOEDERT, J. 1999. HLA and HIV-1: heterozygote advantage and $\mathrm{B}^{*} 35-\mathrm{CW}^{*} 04$ disadvantage. Science 283:1748-1752.

CHAMIZO, E. 2005. Leucosis Bovina Enzootica: Revisión. REDVET-Revista electrónica de veterinária 6:1-25.

EXCOFFIER, L.; LISCHER, H. 2010 Arlequin suite ver 3.5: a new series of programs to perform population genetics analyses under Linux and Windows. Molecular Ecology Resources 10:564-567.

FERNÁNDEZ, I.; RIOS, J.; GAYOSSO, A.; ULLOA, R.; ALONSO, R. 2008. Polymorphism of locus DRB3.2 in populations of Creole Cattle from Northern Mexico. Genetics and molecular biology 31:880-886.

GIOVAMBATTISTA, G.; GOLIJOW, C.; DULOUT, F.; LOJO, M. 1996. Gene frequencies of DRB3.2 locus of Argentine Creole cattle. Animal Genetics 27:55-56.

GÓMEZ, S.; TRUJILLO, E.; DURÁN, C. 2006. Polimorfismos de BoLA-DRB3 en el bovino sintético colombiano Lucerna y asociación con conteo de células somáticas y mastitis. Revista Colombiana de Ciencias Pecuarias 19:270-279.

GRIFFITHS, I.; GALLEGO, M.; VILLAMIL, L. 1995. Factores de infertilidad y pérdidas económicas en ganado de leche en Colombia. División de Disciplinas Pecuarias. ICA pp. 82.

HEDRICK, P.; WHITTAM, T.; PARHAM, P. 1991. Heterozygosity at individual amino acid sites: extremely high levels for HLA-A and -B genes. Proceedings of the National Academy of Sciences 88:5897-5901.

HERNÁNDEZ, D.; POSSO, A.; BENAVIDES, J.; MUÑOZ, J.; GIOVAMBATTISTA, G.; ALVAREZ, L. 2011. Detección del virus de la leucosis bovina en ganado criollo colombiano mediante PCR-anidado. Acta Agronómica 60:312-318.

HERNÁNDEZ, D.; POSSO, A.; MUÑOZ, J.; GIOVAMBATTISTA, G.; ALVAREZ, L. 2013. Polimorfismos del gen BoLADRB3.2* en ganado criollo Colombiano. Revista MVZ Córdoba 18(Supl): 3665-3671.

HRABER, P.; KUIKEN, C.; YUSIM, K. 2007. Evidence for human leukocyte antigen heterozygote advantage against hepatitis C virus infection. Hepatology 46:1713-1721.

HUGHES, A.; NEI, M. 1989. Nucleotide substitution at major histocompatibility complex class II loci: evidence for overdominant selection. Proceedings of the National Academy of Sciences 86:958-962.

INTERNATIONAL SOCIETY FOR ANIMAL GENETICS. [en línea] [Fecha de acceso 20 de Julio de 2010]. URL disponible en http://www.projects.roslin.ac.uk/bola/bolahome.html

JULIARENA, M.; POLI, M.; SALA, L.; CERIANI, C.; GUTIERREZ, S.; DOLCINI, G. 2008. Association of BLV infection profiles with alleles of the BoLA-DRB3.2 gene. Animal Genetics 39:432-438.

KELLY, L.; D’ANGELO, M.; NIMO, A.; PIAGGIO, J.; POSTIGLIONI, A.; NICOLINI, P. 2003. Polimorfismo del gen DRB3.2 en bovinos criollos del Uruguay. Archivos de zootecnia 52:77-80.

LEWIN B. 2009. Genes IX. Mc Graw Hill. 9 ed. pp 203.

MALATESTINIC, A. 2003. Bilateral exophthalmos in a Holstein cow with lymphosarcoma. Canadian Veterinary Journal 44:664-666.

MARTÍNEZ, R.; TORO, T.; MONTOYA, F.; BURBANO, M.; TOBÓN, J.; ARIZA, F. 2005. Caracterización del locus BoLADRB3 en ganado criollo Colombiano y asociación con resistencia a enfermedades. Archivos de Zootecnia 54:349-356.

MIYASAKA, T.; TAKESHIMA, S.; JIMBA, M.; MATSUMOTO, Y.; KOBAYASHI, T.; MATSUHASHI, T.; SENTSUI, H.; AIDA. 
Y. 2013. Identification of bovine leukocyte antigen class II haplotypes associated with variations in bovine leukemia virus proviral load in Japanese Black cattle. Tissue Antigens 81:72-82.

MUÑOZ, D.; POSSO, A.; MUÑOZ, J. 2008. Detección de la leucosis bovina utilizando reacción en cadena de la polimerasa. Revista Colombiana de Ciencias Pecuarias 21:153-161.

NASCIMENTO, C.; MACHADO, M.; MARTINEZ, M.; SILVA, M.; GUIMARÃES, M.; OLIVEIRA, D. 2006. Association of the bovine major histocompatibility complex (BoLA) BoLA-DRB3 gene with fat and protein production and somatic cell score in Brazilian Gyr dairy cattle (Bos indicus). Genetics and Molecular Biology 29:641-647.

GILLET, N.; FLORINS, A.; BOXUS, M.; BURTEAU, C.; NIGRO, A.; VANDERMEERS, F.; BALON, H.; BOUZAR, A.; DEFOICHE, J.; BURNY, A.; REICHERT, M.; KETTMANN, R.; WILLEMS, L. 2007. Mechanisms of leukemogenesis induced by bovine leukemia virus: prospects for novel anti-retroviral therapies in human. Retrovirology 4:18-26.

PANEI, C.; SUZUKI, K.; ECHEVERRIA, M.; SERENA, M.; METZ, G.; GONZALES, E. 2009. Association of BoLA-DRB3.2 alleles with resistance and susceptibility to persistent lymphocytosis in BLV infected Cattle Argentina. International Dairy Journal 4:123-128.

RAMÍREZ, N.; GAVIRIA, G.; RESTREPO, L.; GÓMEZ, C. 2002. Diagnostico epidemiológico referente a varias patologías de bovinos en tres haciendas de la universidad de Antioquia. Facultad de Ciencias Agrarias. Universidad de Antioquia, Medellin. pp. 36.

RIPOLI, M.; LIRÓN, J.; DE LUCA, J.; ROJAS, F.; DULOUT, F.; GIOVAMBATTISTA, G. 2004. Gene Frequency Distribution of the BoLA-DRB3 Locus in Saavedreño Creole Dairy Cattle. Biochemical Genetics 42:231-240.

RUIZ, I. 1995. Avance de resultados municipio de San José de la Montaña. Estudio de infertilidad bovina en las zonas lecheras de Antioquia. Facultad de Ciencias Agrarias. Universidad de Antioquia. Medellin. pp. 29.

RUSSELL, G.; SMITH, J.; OLIVER, R. 2004. Structure of the BoLA-DRB3 gene and promoter. European Journal of Immunogenetics 31:145-151.

SCHELL, M.; HECKERT, H.; MÜLLER, K. 2004. Case report: lymphosarcoma in a cow. DTW. Deutsche tierarztliche Wochenschrif0. 111:38-41.

SULIMOVA, G.; UDINA, I.; SHAIKHAEV, G. 1995. DNA polymorphism at the BoLA-DRB3 gene of cattle in relation to resistance and susceptibility to leukemia. Journal Name: Russian Journal of Genetics 31(9):1105-1109.

TAKESHIMA, S.; AIDA, Y. 2006. Structure, function and disease susceptibility of the bovine major histocompatibility complex. Animal Science Journal. 77:138-150.

TAKESHIMA, S.; MATSUMOTO, Y.; CHEN, J.; YOSHIDA, T.; MUKOYAMA, H.; AIDA, Y. 2008. Evidence for cattle major histocompatibility complex (BoLA) class II DQA1 gene heterozygote advantage against clinical mastitis caused by Streptococci and Escherichia species. Tissue Antigens 72:525-531.

XU, A.; VAN EIJK, M.; PARK, C.; LEWIN, H. 1993. Polymorphism in BoLA-DRB3 exon 2 correlates with resistance to persistent lymphocytosis caused by bovine leukemia virus. The Journal of Immunology 151:6977-85.

ZAMBRANO, J.; ECHEVERRI, J.; LOPEZ, A. 2009a. Asociación de los alelos del gen BoLA DRB3.2 con características productivas en vacas del hato Paysandú de la Universidad Nacional de Colombia. Revista Colombiana de Ciencias Pecuarias 22:448-449.

ZAMBRANO, J.; ECHEVERRI, J.; LOPEZ, A. 2009b. Análisis y frecuencias de los alelos del antígeno leucocitario bovino BoLA DRB3.2 en vacas del hato Paysandú de la Universidad Nacional de Colombia. Revista Colombiana de Ciencias Pecuarias 22:448-449.

ZANOTTI, M.; POLI, G.; PONTI, W.; ROCCHI, M.; LEWIN, H.; VAN EIJK, M. 1996. Association of BoLAclass II haplotypes with subclinical progression of bovine leukaemia virus infection in Holstein-Friesian cattle. Anim Genet. 27:337 - 341. 